This is a pre-copy-editing, author-produced PDF of an article accepted for publication in The British Journal of Occupational Therapy following peer review.

The definitive publisher-authenticated version is: Watson J (2005) Supporting Success in Diverse Student Populations. British Journal of Occupational Therapy, 68(1), p 34-38.

\title{
Supporting Success in Diverse Student Populations.
}

\author{
Jo Watson
}

Practice Evaluation

Education

Word Count: 1995

Jo Watson MSc, BAppSc (OT) Lecturer in Occupational Therapy

\author{
University of Southampton \\ Highfield \\ Southampton, SO17 1BJ \\ email: jdw@soton.ac.uk \\ ph: 02380595303 \\ fax: 02380595301
}




\section{Abstract}

Government agendas seek to widen participation in university education. Reforms of the NHS incorporate a commitment to increase the number of occupational therapists being educated. As a result, the nature of recruitment is changing, with an increasing number of students commencing occupational therapy undergraduate programmes with non-traditional entry qualifications. In response to the apparent difficulty with meeting academic requirements experienced by some of these students, the School of Health Professions \& Rehabilitation Sciences at the University of Southampton developed an innovative 'Summer School' aimed at easing the transition into higher education. Evaluation of participant feedback gathered via questionnaires at two points during their first year indicates the course's potential for preparing students with non-traditional entry qualifications for study at undergraduate level. 


\section{Introduction}

Following the recommendations set out in the 1997 Dearing Report of the National Committee of Inquiry into Higher Education (NCIHE 1997) there has been a commitment from the Government to widening participation in higher education. The concept of 'widening participation' involves actively encouraging and enabling members of under-represented and disadvantaged groups to participate successfully in further and higher education. These groups are highlighted as including mature students, those from less privileged socioeconomic groups and ethnic minorities, those with disabilities and those with non-traditional entry qualifications (NCIHE 1997).

In conjunction with this agenda for education, and as part of its sweeping reforms of the health service, the Government has acknowledged a shortage of the human resources which are so crucial to delivering its programme of modernisation. It made a commitment to expanding the workforce and promised that by 2004 there will be " $\ldots$ over 6,500 more therapists and other health professionals ....and nearly 4,500 more therapists and key professional staff being trained" (DoH 2000b, p 50). In order to meet these targets, the Government called for both a wider recruitment base that reflects society's cultural diversity, and for more effective support from within educational programmes to reduce student attrition rates (DoH 2000a).

These two separate calls for the expansion and diversification of the student population occur against a nation-wide background of diminishing applications 
for occupational therapy (OT) pre-registration programmes (Craik \& Ross 2003). In order to meet government demands and to fill available places the recruitment net needs to be cast ever-wider. OT programmes have responded to this call with an increasing number of students having non-traditional entry qualifications (that is: non A-level qualifications such as General National Vocational Qualifications, Access Certificates, BTEC (Business \& Technician Education Council) Diplomas and Higher National Certificates \& Diplomas).

These students may have a wealth of life experience which will enhance the way they manage themselves and their learning, but often have little experience of post-compulsory education prior to any recent studies specifically aimed at university entry. Many have completed practically or vocationally oriented courses of study which tend to offer higher levels of individual support and guidance, and operate within a different educational and assessment culture than students encounter in higher education (Brooks 2003; Hatt \& Baxter 2003).

It is widely acknowledged that in actively encouraging participation by a broader spectrum of students, those with non-traditional entry qualifications may experience particular difficulties in making a successful transition into higher education. Particular challenges are experienced with skills such as time management and organisation, self-directed study, academic writing, referencing, revision and exam technique, and search skills using library and electronic sources (NCIHE 1997; HEFCE 2002; HEFCE 2001; Price \& Phillips 2001). Evidence from non-completion rates would suggest that students from 
these groups are more likely to withdraw from courses, whether voluntarily or involuntarily due to academic failure (NCIHE 1997).

In order to successfully increase and diversify the OT workforce, it therefore becomes imperative that educators respond to the expanding diversity of the student population by reviewing learning \& teaching strategies, and by addressing the development of the learning skills and confidence that is so often required if students from non-traditional backgrounds are to succeed. This paper describes an evaluation of one such initiative at the School of Health Professions and Rehabilitation Sciences at the University of Southampton, a short course known as 'Summer School'.

\section{Developing the Summer School course}

In the School of Health Professions and Rehabilitation Sciences it had become evident that a significant proportion of students from non-traditional backgrounds were having difficulty managing the academic requirements of the first year of their undergraduate studies. Limited study skills were noted to crystallize particularly within the study of anatomy and physiology in the Biological Sciences module, especially for those who had no prior experience of studying biology. A high proportion of students voluntarily withdrawing from the programme cited this as a specific area of difficulty prompting their decision. Involuntary withdrawal due to academic failure in the first year was also skewed towards this demanding area of the syllabus. 
With a commitment to both the widening participation agenda and to taking active steps to minimise non-completion rates, it was acknowledged that additional support was likely to be required by these students. Gaps identified in students' previous academic experience included the ability to summarise and take concise notes, the ability to identify and effectively utilise appropriate learning resources, an understanding of the nature of and need to be selfdirected learners and a general appreciation of the functioning and organisation of the human body. An innovative short course known as 'Summer School' was designed to address these needs.

Summer School was offered for the first time to students with non-traditional entry qualifications who were commencing their undergraduate studies in the $2002 / 3$ academic year. In response to local observations of the difficulties experienced students without a solid background in Biology, the invitation was also extended to school leavers in this category. Students were advised that participation in Summer School was completely voluntary; and that they would not be penalised in any way should they chose to decline the offer.

The aims of the course were:

- To orientate students to the University \& the School

- To provide a structured induction to the learning resources available

- To develop \& extend initial study skills

- To provide a foundation \& introduction to Biological Science 
The course ran over eight days immediately prior to standard Freshers' Induction days occurring at the beginning of year one of the undergraduate programme, and offered structured learning \& teaching activities each morning. Students were asked to complete directed tasks each afternoon in order to consolidate their learning and to employ the new skills and access the new resources that they had been introduced to. Keeping the afternoons 'free' also provided an opportunity for students to familiarise themselves with the campus and the local area. A summary of the course content is provided in Table 1.

Thirty of the seventy students commencing the OT programme were invited to attend the inaugural Summer School based on the nature of their entry qualifications. These students were systematically selected where they were not entering with A-level qualifications, where their A-levels did not include Biology, or where the result achieved in Biology was at a $\mathrm{D}$ grade or lower. Fourteen of the thirty students invited chose to take up the offer. Two deferred their undergraduate places until the following year; and two declined the undergraduate place offers made.

\section{Evaluation}

Attendance during the course was high, and students engaged well during the sessions and with the directed tasks. Anonymous feedback was gathered from students using questionnaires immediately at the completion of Summer School and further into their undergraduate studies in order to reflect upon possible longer-term benefits during their first year of study. 
Analysis of the immediate feedback received was favourable, with all of the participants returning the evaluation questionnaire. The questionnaire used was non-standardised, and incorporated both open and closed questions asking students to rate aspects of the course on a five point Likert scale (Appendix A). The students unanimously felt more confident about commencing undergraduate studies, felt better prepared, and were confident that they would know how and where to access help should it be required in the future.

Reflective feedback on the value of attending Summer School was requested after fourteen weeks, following the students' first examination, but prior to the results being released. A similar non-standardised questionnaire format was used, again incorporating both open and closed questions (Appendix B). On this occasion students were asked to rate the perceived benefits of participating in Summer School on a five point Likert scale and to reflect on the value of individual components of the course. Eleven of the fourteen, or $79 \%$ of the participants responded.

The feedback received was again very positive, with students making comments such as:

"If I had not attended Summer School, I would be totally out of my depth."

"It was a brilliant introduction \& made me thirsty to get started \& learn." 
Students endorsed the concept of Summer School, recommending its continuation for future intakes. On a Likert scale of 1 to 5 (with 5 being very valuable), students' average rating of the overall value of Summer School was 4.91 .

Experience indicates that students' first examination in Biological Sciences tends to prove particularly challenging, so the results achieved were also considered in an effort to evaluate the effectiveness of Summer School. Figure 1 provides a visual representation of the results of students who attended Summer School and those of students who were offered but declined a place on the short course. A Mann-Whitney $U$ test was applied to this data to compare the results of the two groups and revealed no statistical significance between the groups $(p=0.23)$. This suggests that any variation in results between the two groups is due to chance alone, indicating that attending Summer School had no apparent impact on academic performance in this subject area.

Figure 2 reveals the broad spread of marks achieved by both groups of students which would tend to suggest the need to refine the selection criteria for Summer School, and to reconsider the content of the course to ensure that the stated aim of developing study skills is met. 


\section{Moving Forward}

Initial experiences of Summer School have resulted in the course being refined to place much greater emphasis on the development of study skills, with less attention being paid to the introduction of syllabus content. Developing generic, transferable study skills will enable students to take greater responsibility for their own learning and to deal appropriately with a variety of subject areas as they emerge during the course of their studies. Elements of the syllabus remain, such as introductions to anatomical terminology and the musculoskeletal and nervous systems, but are used as tools to encourage students to practice and develop particular study skills, rather than as ends in themselves. Components of Summer School that were successful, such as orientation to the higher education environment and the learning resources available have been retained.

The criteria for invitation have been refined in recognition that graduate students entering the OT programme are equipped with the necessary study skills to succeed regardless of having a background including biology or not. Accurately identifying students at risk of academic failure will take time and involve ongoing audit of the academic results achieved by students with differing entry qualifications.

This practice evaluation report represents the initial stages of developing more rigorous designs to appraise the effectiveness of this course. Further consideration needs to be given to how to effectively capture the outcomes of 
Summer School, and to understanding how students from non-traditional backgrounds experience higher education in order to establish how best to support their learning on an ongoing basis.

\section{Conclusion}

Occupational therapy educators have a responsibility to both the profession and to supporting their institutions' efforts to fulfil government ambitions to increase the number of therapists and to widen participation in higher education. Thankfully at present these driving forces are broadly similar with regard to the aim of increasing the diversity of the pre-registration student population. However, in order to successfully increase the number of occupational therapists qualifying to practice and to expand the diversity of the professional workforce, it is necessary not only to raise the aspirations of a broader range of potential students, but to provide mechanisms that support and facilitate them through to graduation.

Whilst it is possible to learn from the evidence starting to accumulate regarding good practice in supporting the widening participation agenda (HEFCE 2002), little has so far emerged relating specifically to OT programmes. Having participated in activities that raise the aspirations and expectations of students, the evolving programme of Summer School provides a potential model for a positive first step towards meeting our obligation to support and facilitate those whose aspirations we have raised. The occupational therapy profession and workforce have a lot to gain by doing so. 


\section{Acknowledgements}

The author wishes to thank Dr Claire Ballinger for her encouragement, support and guidance in the preparation of this paper. Thanks are also extended to the two anonymous reviewers who provided helpful feedback on an earlier draft of this paper. 


\section{References}

Brooks, Rachel (2003) The Experiences of Non-Traditional Students at the University of Surrey. Available at: www.surrey.ac.uk/EdLiaison/wp.html Accessed: 7.11 .03

Craik, C \& Ross, F (2003) Promotion of Occupational Therapy as a Career: a Survey of Occupational Therapy Managers. British Journal of Occupational Therapy, 66(2), 78-81.

Department of Health (2000a) Meeting the Challenge: A Strategy for the Allied Health Professions. London: Department of Health.

Department of Health (2000b) The NHS Plan: A plan for investment, a plan for reform. London: Her Majesty's Stationery Office.

Hatt, Sue \& Baxter, Arthur (2003) From FE to HE: Studies in Transition. A comparison of students entering higher education with academic and vocational qualifications. Widening Participation and Lifelong Learning, 5(2), 18-29.

Higher Education Funding Council for England (2001) Strategies for Widening Participation in Higher Education. A Guide to Good Practice. Bristol: HEFCE.

Higher Education Funding Council for England (2002) Successful Student Diversity. Bristol: HEFCE. 
National Committee of Inquiry into Higher Education (1997) Higher Education in the Learning Society. (The Dearing Report). London: Her Majesty's Stationery Office.

Price, G.A. \& Phillips, P. (2001) Report: Audit of Study Skills May 2001. Available at: www.clt.soton.ac.uk/qau/qa guidance/study skills Audit.doc Accessed: 29.10 .02 
TABLE 1: Summer School Course Content

\begin{tabular}{|c|l|}
\hline DAY & \multicolumn{1}{|c|}{ CONTENT } \\
\hline 1 & Study Skills \\
\hline 2 & Introduction to electronic \& multi-media learning resources \\
\hline 3 & Library Induction \\
\hline 4 & Introduction to foundation sciences \& anatomical terminology \\
\hline 5 & Review of the organisation of cells into tissues \& systems \\
\hline 6 & Introduction to the musculoskeletal \& nervous systems \\
\hline 7 & Introduction to the Dissecting Room \\
\hline 8 & Review of Study Skills \\
\hline
\end{tabular}


FIGURE 1: Box Plot of the examination results achieved by those attending \& those who were invited but declined to attend Summer School.

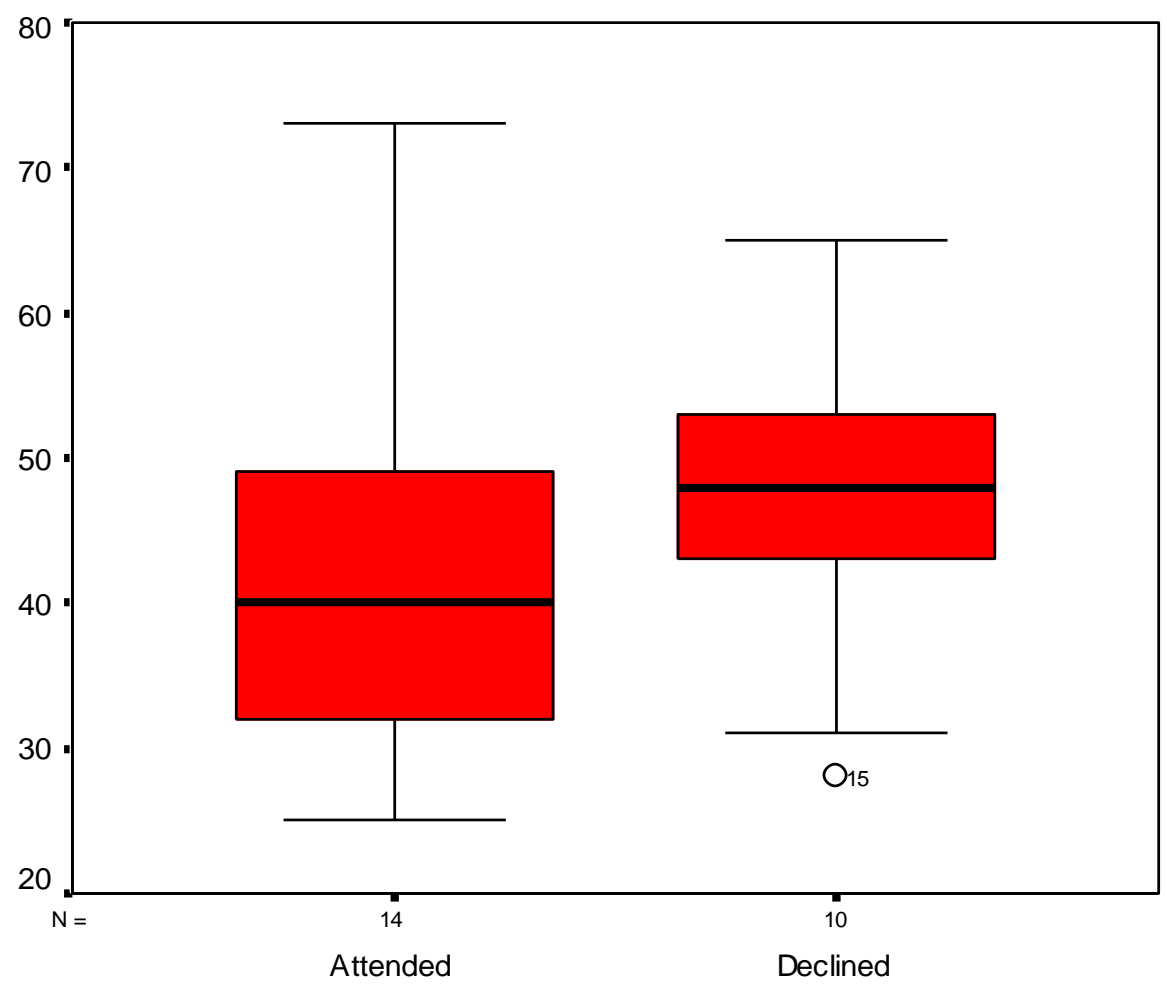

$U=49.500, p=0.230$

Notes: The central boxes represent the range of scores within which $50 \%$ of each group fell; with the line inside each box indicating the median score. The whiskers extending from the boxes indicate the maximum and minimum scores within each group. The circle labelled ' 15 ' indicates an extreme score for participant No. 15 which was significantly different from others within that group. 
FIGURE 2: Bar Graph indicating the spread of results for Biological Sciences.

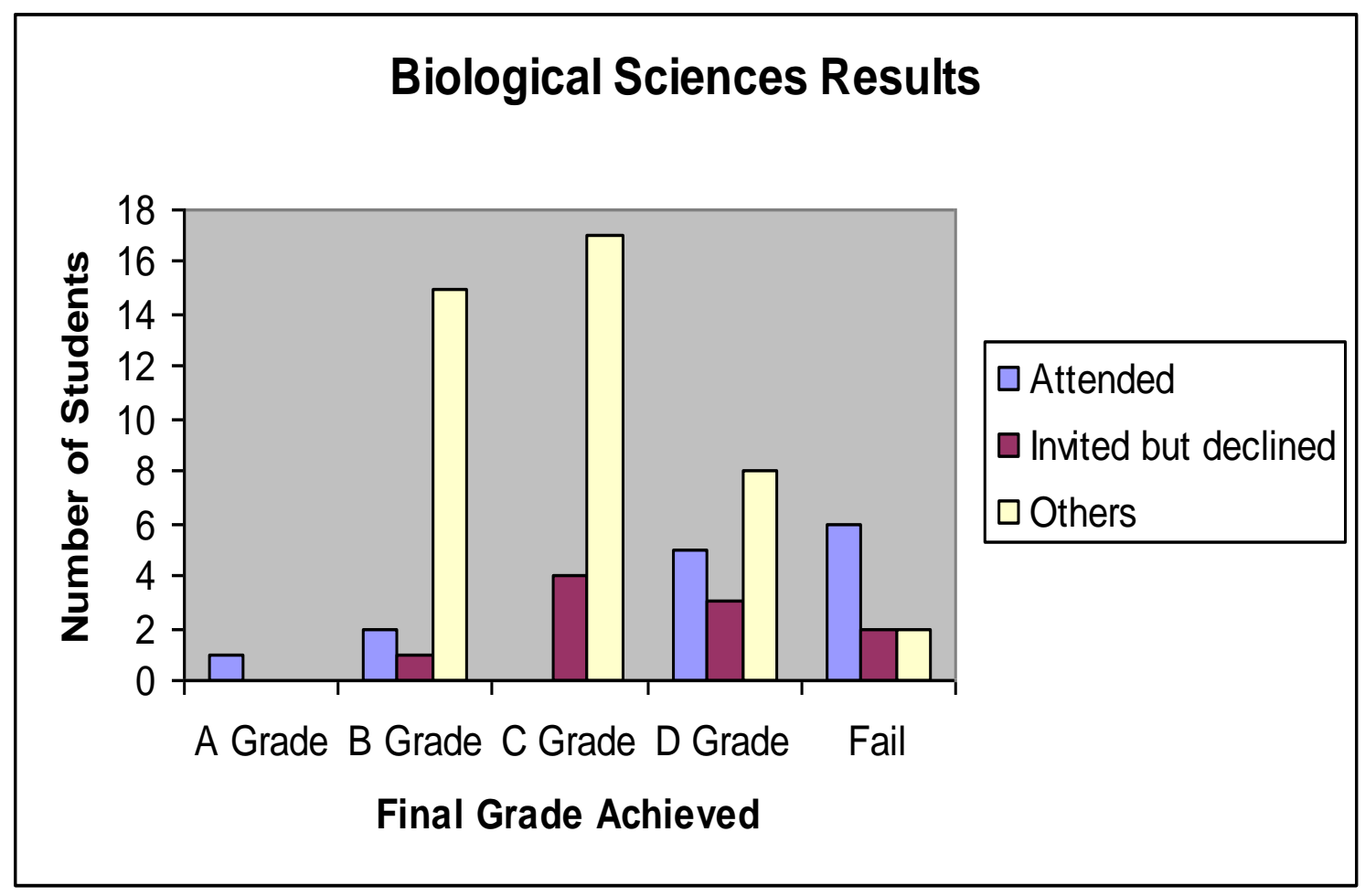

